STUDI

FRANCESI

\section{Studi Francesi}

Rivista quadrimestrale fondata da Franco Simone

194 (LXV | II) | 2021

Baudelaire et son cénacle

\title{
Studi sulla Letteratura Cavalleresca in Francia e in Italia (secoli XIII-XVI). Volume 2, a cura di M. LECCO
}

\author{
Maria Colombo Timelli
}

\section{OpenEdition}

\section{Journals}

\section{Édition électronique}

URL : https://journals.openedition.org/studifrancesi/44585

DOI : 10.4000/studifrancesi.44585

ISSN : 2427-5856

\section{Éditeur}

Rosenberg \& Sellier

\section{Édition imprimée}

Date de publication : 1 août 2021

Pagination : 343-344

ISSN : 0039-2944

\section{Référence électronique}

Maria Colombo Timelli, « Studi sulla Letteratura Cavalleresca in Francia e in Italia (secoli xIII-xvı). Volume 2, a cura di M. LECCO », Studi Francesi [En ligne], 194 (LXV | II) | 2021, mis en ligne le 06 septembre 2021, consulté le 14 octobre 2022. URL : http://journals.openedition.org/studifrancesi/44585 ; DOI : https:// doi.org/10.4000/studifrancesi.44585

Ce document a été généré automatiquement le 14 octobre 2022.

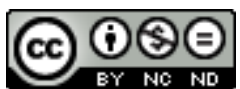

Creative Commons - Attribution - Pas d'Utilisation Commerciale - Pas de Modification 4.0 International - CC BY-NC-ND 4.0

https://creativecommons.org/licenses/by-nc-nd/4.0/ 


\title{
Studi sulla Letteratura Cavalleresca in Francia e in Italia (secoli XIII-XVI). Volume 2, a cura di M. LECCO
}

\author{
Maria Colombo Timelli
}

\section{RÉFÉRENCE}

Studi sulla Letteratura Cavalleresca in Francia e in Italia (secoli XIII-XVI). Volume 2, a cura di M. LECCO, Alessandria, Edizioni dell'Orso, 2019, 200 pp.

1 Faisant suite à un recueil d'articles au même titre paru en 2017, ce deuxième volume confirme l'intérêt d'un sujet où de nombreuses pistes restent à explorer sur la circulation de textes, thèmes et motifs, tant en diachronie qu'en diatopie. Nous nous limitons ici à signaler les articles portant sur le Moyen Âge français.

Andrea GHIDONI (Perché i figli di Aymeri lasciano Narbonne? Evoluzioni di un 'mythe familial' tra Francia, Italia e Spagna, pp. 1-22). Le 'mythe familial' des Aymérides se fonde sur un récit initiatique déjà étudié par Joël H. Grisward (1981 et 2006); A.G. élargit ici l'enquête pour s'interroger sur un corpus français (Narbonnais et Enfances Guillaume, XII ${ }^{e}$-XIII siècles), italien (Morte di Carlo Magno, Storie Nerbonesi d'Andrea de Barberino, tous les deux du XIV ${ }^{e}$ siècle) et espagnol ('romance' Ese buen Diego Laínez, XIV siècle). Si ce dernier texte doit finalement être exclu, puisque le departement ne touche pas une fratrie mais bien un seul enfant, les autres récits se rattachent à un noyau original l'initiation des enfants à la cour de Charlemagne - qu'un intermédiaire sans doute franco-italien aurait enrichi par des motivations diverses: la vengeance du père et la défense de la monarchie féodale.

Federico GUARIGLIA (Appunti sulla tradizione del "Gui de Nanteuil": nuove ricerche, pp. 23-58). Ce long article, préliminaire à une thèse de doctorat en cours, présente la tradition manuscrite de Gui de Nanteuil, en se concentrant d'abord sur les deux manuscrits complets, et en particulier sur le manuscrit conservé à Venise, qui ajoute un prologue 
de presque 1000 vers contenant le résumé de la seconde partie de la chanson Aye d'Avignon et quelques laisses anecdotiques; ces ajouts, dont la langue est fortement italianisée, se distinguent nettement du contexte, transmis par le manuscrit de Montpellier, qui fournira le texte de base pour l'édition. Reliquats d'une tradition certainement plus riche, deux fragments et une copie d'une centaine de vers fournie par Fauchet. Dans l'impossibilité de reconstruire un stemma, l'éditeur critique ne pourra cependant ignorer aucun de ces témoins, vestiges d'une diffusion vaste, aussi bien en France qu'en Italie.

4 Cesare MASCITELLI (Alcune ipotesi sulla circolazione 'extravagante' del "Faucon de Candie" $e$ della "Bataille d'Aliscans" in Italia, pp. 73-89) s'interroge sur les particularités de la circulation italienne de Faucon de Candie et des Aliscans. Tout d'abord, cette diffusion se fit dans des témoins qui isolent chaque chanson de son cycle. Une première explication tient sans doute à leur longueur même (quelque 15000 vers pour Faucon, dont est conservé au moins un manuscrit de petit format), mais une des raisons de leur succès tient sans doute à l'influence majeure exercée par la Commedia de Dante, qui fait allusion à deux endroits (Enfer IX et Paradis XVIII) à cette matière épique, ainsi que par ses commentateurs. Cela peut avoir déterminé un renouveau d'intérêt auprès d'un lectorat cultivé et noble, trois manuscrits $\mathrm{du} \mathrm{xIV}^{\mathrm{e}}$ siècle ayant appartenu aux Gonzagues. 